\title{
PERAN DIPA NUSANTARA AIDIT PADA PERISTIWA BERDARAH G30S TAHUN 1965
}

\author{
Muhammad Ihsan Aulia, * Samsudin.**Widiati Isana \\ Fakultas : Adab dan Humaniora UIN Sunan Gunung Djati Bandung. \\ Email: m.ihsanaulia07@gmail.com
}

Abstract

Dipa Nusantara Aidit was a figure in the Indonesian Communist Party since 1947. His role was very important in the events of the G30S in 1965, especially because of his political movements that resulted in the event. This writing aims to determine the biography of Dipa Nusantara Aidit and how the role of Dipa Nusantara Aidit in the G30S incident in 1965. The method used in this study is the historical method. The results of this study Dipa Nusantara Aidit was a communist figure in the Indonesian Communist Party, active in Menteng 31 by establishing Gerindom (Gerakan Indonesia Merdeka) then establishing PBK (Persatuan Buruh Kendaraan), establishing API (Angkatan Pemuda Indonesia), and LEKRA. He once served as CC PKI Secretary General and Deputy Chair of the MPRS. Aidit was also active in writing books, among his works were the History of the Indonesian Workers' Movement, Taking the Way of the Rakya, Towards a New Indonesia, the Birth of the PKI and Its Development, and the Peasants Extending Village Demons. Second, D.N. Aidit in 1953 deposed Alimin and became CC PKI Secretary General through the Plenary Session. Aidit launched various revolutionary offensive from January to September 1965. Aidit through the PKI launched various issues such as forming Force V, Nasakom and the Council of Generals which later became a bloody coup in the kidnapping of generals on October 1, 1965. Although in the end Aidit himself was captured and was killed in Boyolali on November 22, 1965.

Keywords: Aidit, General Council, PKI. 


\section{Pendahuluan}

Gerakan 30 September merupakan peristiwa penting dan bukan hanya bagi bangsa Indonesia. Duta Besar Amerika Serikat untuk Indonesia pada tahun 1965, Marshall Green, berpendapat bahwa G30S merupakan peristiwa yang membahayakan AS semasa perang dingin. Ia mengartikan gerakan tersebut adalah usaha kudeta dari komunis yang jika berhasil dilakukan akan merubah wajah Indonesia yang kemudian akan bersekutu dengan Uni Soviet atau Tiongkok.

Suatu Progress Report National Security Council mengenai politik Amerika di Indonesia mencatat "bahwa Partai Komunis Indonesia menyatakan anggotanya meningkat dari kira-kira 126.000 menjadi 165.000 dalam waktu setahun". Pada tahun 1965, PKI menyatakan anggotanya berjumlah 3.5 juta orang anggota penuh, dan pendekatan 20 juta orang anggota yang berafiliasi pada organisasi seperti SOBSI, GERWANI, dan Pemuda Rakyat.

Pimpinan PKI menaruh perhatian mendalam terhadap kabar burung tentang kudeta. Ketua CC-PKI DN Aidit pada pertengahan 1965, mencari informasi yang lebih tepat dan konkret. Ia memerintahkan Sjam Kamaruzaman agar BC-PKI menyelidiki jaringannya dalam kalangan militer dan badan-badan intelejen untuk mencari tahu tentang kebenaran kabar burung tersebut. BC-PKI yang semula dipimpin Karto dari awal 1950an sampai sekitar 1963-1964, telah mengembangkan jaringan luas di kalangan para perwira yang bersedia memberikan informasi intelejen kepada PKI.

Metode yang dipergunakan dalam penelitian ini adalah metode sejarah. Metode penelitian ini dilakukan melalui empat tahapan, yaitu heuristik (pengumpulan sumber-sumber primer dan sekunder), kritik (intern dan ekstern), interpretasi (menafsirkan sumber-sumber sejarah), dan historiografi (penulisan sejarah).

\section{Pembahasan}

D.N Aidit lahir pada tanggal 30 Juli 1923 di Jalan Belantu Nomor 3 Pangkalalang, Tanjungpandan dengan nama Achmad Aidit. Nama ayahnya adalah Abdullah Aidit. ${ }^{1}$ Ibunya bernama Mailan termasuk keluarga ningrat Belitung, anak seorang dari yang bertitel Ki Agus atau KA, yakni Ki Agus H. Abdul Rachman dan Nyanyu Aminah. Dari perkawinan Abdullah dan Mailan lahirlah empat orang anak yaitu Achmad Aidit, Basri Aidit, Ibrahim Aidit (meninggal ketika kecil), dan Murad Aidit. Abdullah Aidit bekerja sebagai

\footnotetext{
${ }^{1}$ Murad Aidit, Aidit Sang Legenda, Panta Rei, Jakarta, 2005, hlm.33.
} 
mantri kehutanan dengan gaji ketika itu adalah 60 gulden, dengan masa dinas sudah puluhan tahun. ${ }^{2}$

Anak-anak remaja di kampung Aidit terbagi menjadi empat golongan yaitu, pertama golongan anak kampung (pribumi), Aidit termasuk golongan ini. Kedua adalah golongan anak benteng (anak tangsi) yang terdiri atas anakanak polisi yang mendiami tangsi, umumnya adalah polisi yang datang dari pulau Jawa.. Ketiga, golongan anak Tionghoa yang tinggal dipasar adalah pedagang dikota tersebut. Golongan keempat dikenal sebagai anak Sekak, tinggal di suatu daerah perkampungan Sekak yang bernama Birok.

Awal 1948, Aidit berumur 25 tahun, dan Soetanti berumur 24 tahun, menikah secara Islam tanpa pesta, dirumah KH Raden Dasuki, sesepuh PKI Solo, yang bertindak sebagai penghulu. Moedigdo, Aminah dan empat orang adik Soetanti datang. Hanya Murad dan Sobron, dua adik Aidit yang mewakili keluarga Belitung. ${ }^{3}$

\section{Pendidikan Aidit}

Achmad Aidit kecil menamatkan sekolahnya di HIS (Hollands Inlandsche School) atau sekolah dasarnya anak-anak sekarang. Ketika di Belitung belum ada SMP, Aidit dikirim ke Batavia untuk masuk ke sekolah dagang bernama MHS (Middlestand Handels School). Di Batavia, Aidit mulai berhubungan dengan banyak pemuda, mahasiswa yang bercita-cita patriotik. Bercita-cita memerdekakan diri dari penjajahan Belanda. Hubungannya dengan orang-orang politik semakin bertambah seperti Sukarni, Chaerul Shaleh, Adam Malik, Djohan Nur, dan tokoh-tokoh pemuda pejuang ketika itu. Aidit juga masuk dalam lingkungan Pemuda API yang bermarkas di Menteng 31, dan Soekarno, Muhammad Hatta dan Muhammad Yamin menjadi gurunya waktu itu, terutama Bung Hatta yang menjadikan Aidit sebagai murid kesayangannya meskipun kemudian hari menjadi musuh bebuyutan karena berbeda arah aliran politik.

D.N Aidit menyukai buku-buku klasik tentang politik dan ekonomi. Dia mempelajari berbagai buku yang sifatnya komunis dan sosialis. Dia mulai membaca buku tebal Das Kapital karya Karl Marx (1818-1883), mulai mengenal dan mempelajari pemikiran Friedrich Engels (1820-1895),

\footnotetext{
${ }^{2}$ Sobron Aidit, Aidit (Abang, Sahabat dan Guru di Masa Pergolakan), Nuansa Cendekia, Bandung. 2003, hlm. 24.

${ }^{3}$ Tempo : Orang Kiri Indonesia, Aidit (Dua Wajah Dipa Nusantara), Kepustakaan Populer Gramedia, Jakarta. 2010, hlm.29.
} 
Fuerbach, Friedrich Nietszhe (1844-1900), dan yang lainnya seperti karya Mao Zedong dan pemimpin Tiongkok lainnya. ${ }^{4}$

\section{Karir Politik Aidit}

Aidit terpilih untuk mengikuti kursus-kursus yang diadakan oleh para pemuda "Angkatan Indonesia Baru" yang dilaksanakan di Menteng 31. Asrama ini dikelola oleh Sendenbu (Badan Penerangan Jepang) dimana Sukarni bekerja. Tempat ini adalah tempat penggodogan para pemuda untuk menjadi pemimpin dan memang pada akhirnya banyak alumni Menteng 31 yang menjadi pemimpin, baik pada saat menjelang kemerdekaan 17 Agustus, maupun dalam perjuangan bangsa seterusnya. ${ }^{5}$

Selain Sukarni, sebagai pengurus asrama ini, terdapat pula Chaerul Saleh dan AM Hanafi, serta beberapa yang lain. Siswa-siswa diasramakan di tempat pelatihan itu, hingga pada suatu kesempatan beberapa pemuda sepakat untuk mendirikan Gerindom (Gerakan Indonesia Merdeka). Dewan politiknya dipegang oleh D.N Aidit sebagai ketua, dengan anggota-anggota MH Lukman dan Suko. Sedangkan Dewan Eksekutif dipegang oleh Syamsudin (Chan), Suko dan Sidik Kertapati. Disamping itu, atas inisiatif Angkatan Baru Indonesia ini mengorganisir pembentukan PBK (Persatua Buruh Kendaraan) yang dipimpin oleh Suparjan dan D.N Aidit. Para pengajar di asrama ini antara lain Bung Karno, Bung Hatta, Amir Syarifuddin, Mr. Subarjo dan Mr. Sunaryo. ${ }^{6}$

Pemuda-pemuda bekas Gerindom, diantaranya AM Hanafi, D.N Aidit, Armasnyah, dan pemuda-pemuda sayap kiri dari Indonesia Muda, merupakan inti dari revolusioner dari Angkatan Baru Indonesia. Mereka juga membangun organisasi semi militer yang bernama "Barisan Banteng" yang dipimpin oleh Chalid Rasyidi, D.N Aidit, Salam dan lainlain. Dengan semangat kebangsaan yang tinggi dan paham politik anti fasis maka pengaruhnya cepat tersebar di kalangan rakyat. Dalam aksinya mereka menggunakan nama "Banteng Merah".7

Pada tangal 1 September 1945, Wikana dan kawan-kawan mendirikan API (Angkatan Pemuda Indonesia) yang bertempat di Menteng 31. Pimpinannya waktu itu adalah Wikana sebagai ketua umum, AM Hanafi sebagai sekretaris jenderal, dan DN Aidit sebagai ketua Jakarta Raya.

\section{Karya-karya Aidit}

\footnotetext{
${ }^{4}$ Sobron Aidit, Aidit (Abang, Sahabat dan Guru di Masa Pergolakan),..hlm.43.

${ }^{5}$ Murad Aidit, Aidit Sang Legenda,...hlm.79.

${ }^{6}$ Murad Aidit, Aidit Sang Legenda,....hlm.79.

${ }^{7}$ Murad Aidit, Aidit Sang Legenda,....hlm.80.
} 
Banyak karya-karya buku yang ditulis oleh Dipa Nusantara Aidit sepanjang tahun 1952-1964 diantaranya Kaum Tani Mengganjang SetanSetan Desa (1964), Lahirnja PKI dan perkembangannja (1955), Menudju Indonesia Baru (1953), Menempuh Djalan Rakjat (1952) dan Sejarah Gerakan Buruh Indonesia (1952).

\section{Pengaruh Aidit dalam PKI}

Pada permulaan abad ke-20 muncullah di Indonesia kelas-kelas baru yang menyiapkan diri untuk memegang pimpinan perlawanan terhadap penindasan yang dilakukan oleh imperialisme. Pada tahun 1905 berdirilah serikat buruh yang pertama dengan nama SS-Bond, kemudina berdirilah VSTP di Semarang pada 1908. Kemudian berdirilah ISDV pada tahun 1914 di Semarang yang melahirkan pemimpin revolusioner bangsa Indonesia, dan sayap kiri dari ISDV yang kemudian mempelopori berdirinya Partai Komunis Indonesia pada tahun $1920 .^{8}$

PKI adalah Partai dari kelas baru yaitu kelas buruh, yang diperlukaj untuk memikul pertanggung jawaban pemimpin. Kelas buruh Indonesia walaupun jumlahnya kira-kira 6.000.000 penerima upah dan kira-kira 500.000 buruh modern atau ploretariat, tetapi ia berlainan dengan kaum tani, karena kelas buruh mewakili kekuatan produktif yang baru. Kelas buruh juga tidak seperti kelas Borjuis, sebab kelas ini mempunyai tekad perjuangan yang konsekwen, disebabkan kelas ini menderita tiga macam penindasan, yaitu penindasan Imperialisme, Feodalisme, dan Kapitalisme. Karena pekerjaan dilapangan yang sangat disiplin dan tidak memiliki alat produksi kelas buruh adalah kelas yang paling konsekwen dan tidak individualistis.

Dalam waktu yang tidak lama kaum Komunis sudah mempunyai pengaruh yang besar dalam PPKB (Persatuan Pergerakan Kaum Buruh) yang kongresnya dalam bulan Agustus 1920 di Semarang dihadiri oleh 22 serikat buruh dengan anggota seluruhnya 72.000. Pengaruh kaum Komunis terutama dengan melalui VSTP yang militan. Ini adalah permulaan tradisi PKI yang baik dalam gerakan buruh. ${ }^{9}$ Pada Kongres PKI di Kota Gede, Jogjakarta, bulan Desember 1924 tercatat bahwa Partai ini mempunyai 38 Seksi yang meliputi 1.140 anggota, sedangkan Serikat Rakyat (underbouw PKI), mempunyai 46 Seksi dan meliputi 31.000 anggota.

Pada tanggal 24 Mei 1937 didirikan suatu organisasi bernama GERINDO (Gerakan Rakyat Indonesia) di Jakarta. Dipimpin oleh Adnan

\footnotetext{
${ }^{8}$ D.N. Aidit, Sedjarah Gerakan Buruh Indonesia, Jajasan "Pembaruan", Djakarta, 1952, hlm.38.

${ }^{9}$ D.N. Aidit, Lahirnja PKI Dan Perkembangannja (1920-1955), Jajasan "Pembaruan", Djakarta, 1955,..hlm.12.
} 
Kapau Gani, Mohammad Yamin, Amir Syarifudin, Ki Sarmidi Mangunsarkoro, Sartono, Wilopo, Sanusi Pane. ${ }^{10}$ Gerakan ini juga menciptakan barisan pemuda Gerindo, dimana D.N Aidit mulai menjadi anggota sejak umur 16 tahun. Waktu itu Gerakan Rakyat Indonesia bukan gerakan komunis sekalipun pemimpinnya adalah tokoh komunis.

Pada bulan Januari 1947 dilangsukan Kongres Nasional IV PKI di Solo yang merupakan Markas Besar Partai Komunis Indonesia waktu itu. Kongres ini menghasilkan program "terwujudnya masyarakat sosialis Indonesia" juga menyetujui politik "Perjanjian Linggarjati" yang bersifat kapitulis kaum Imperialis Belanda. Mengenai organisasi, kongres ini masih memakai ketentuanketentuan Anggaran Dasar dan Anggaran Rumah Tangga tahun 1924. Kongres IV memilih CC baru, terdiri dari Sutrisno, Wiranta, Ngadiman Hardjosubroto, Maruto Darusman, Sardjono, Suripno, D.N. Aidit dan lainlain. Sesudah Kongres IV, CC PKI pindah ke Yogyakarta.

Tanggal 21 September 1948, Pemerintah memerintah TNI untuk menumpas pemberontakan PKI di Madiun. Satuan-satuan dari Siliwangi dan Brimob bergerak dari Solo-Sragen-Karanganyar menuju ke timur, sedang satuan-satuan dari Brigade "S" (Surachmat), dengan 5 batalyon: Sunarjadi, Sobiran, Sabarudin, Sumadi, dan Branjangan, Divisi VI Brawijaya bergerak dari Kediri ke barat. Kolonel Sungkono segera sadar untuk memimpin penumpasan. Sementara kaum komunis di Banten dan Tapanuli juga bergerak. Jusuf Adjitorob dikirim ke Sumatra Utara, dan berdiam di Medan, tempat pendudukan Belanda. Dari situ ia mau menggerakkan kaum komunis. Amir Sjarifudin, berbicara lewat Radio Madiun "Serang terus" sebagai reaksi atas keputusan Yogyakarta itu, dan seperti Suripno ia katakan sekalipun terima tantangan Yogyakarta, "Konstitusi Republik adalah konstitusi kita, dan bendera Merah Putih bendera kita." Sedang di daerah Madiun dan sekitarnya telah berkibar bendera merah-palu-arit. ${ }^{11}$

Pada 24 September 1948, Kudus dikuasai FDR/PKI. Pati dikuasai tanggal 25 September 1948 dan menyusul untuk kota-kota Blora, Rembang, Randublatung Purwodadi, dan Cepu. Khusus wilayah Cepu, pasukan proPartai Komunsi Indonesia terdiri dari kesatuan Brigade Sudiarto, Laskar Minyak, Pesindo, SOBSI, Buruh Kereta Api, Buruh Kantor Telepon, buruh PLN, buruh Kehutanan dan lain-lain. Perebutan kekuasaan yang dilakukan FDR/PKI ini tentu saja mendaptkan perlawanan sengit dari pasukan TNI. Pertempuran paling dahsyat terjadi di kota Cepu. Dalam pertempuran ini, saling berhadap-hadapan antara pasukan pro-PKI dibantu Laskar Minyak

\footnotetext{
${ }^{10}$ Wikipedia, Gerakan Rakyat Indonesia, diakses dari https://id.m.wikipedia.org, pada tanggal 25 Mei 2019 pukul 17.00.

${ }^{11}$ Soegiarso Soerojo, Siapa Menabur Angin Akan Menuai Badai (G30S/PKI dan Apa Peran Bung Karno),..hlm.70.
} 
melawan TNI yang terdiri dari Brigade Ronggolawe, Kompi Bantuan Pimpinan Letnan Rianto, dan Brigade II/Siliwangi yang telah menguasai Madiun. Batalyon Daeng yang telah menguasai Masopati, Batalyon Kemal Idris dari Randublatung dan pasukan-pasukan lain dari sekitar Cepu. ${ }^{12}$

Pada Hari Buruh 1 Mei 1950 ini terbit majalah Pekerdja dengan istimewanya yang dipimpin oleh Mhd. Munir. Tanggal 15 Agustus 1950 terbit majalah teori Bintang Merah yang pertama dan dipimpin oleh D.N. Aidit, Lukman, Njoto, dan Peris Pardede. Tanggal 17 Agustus 1950, LEKRA (Lembaga Kebudajaan Rakjat) didirikan oleh D.N. Aidit, Njoto, Jubaar Ajub, Henk Ngantung, Sudjojono, dan sebagainya. Pada tanggal 7 Januari 1951 PKI mengundang Sidang Pleno CC. Di situ Aidit dengan dukungan dari golongan muda seperti Wikana, Njoto, Lukman, berhasil menggeser Alimin. Aidit mengoreksi kesalahan politik dan organisasi yang dibuat CC. Sesudah merebut pimpinan partai, D.N. Aidit mulai kampanye menghilangkan sebutan pemberontakan Madiun. ${ }^{13}$

Pada Sidang Pleno CC PKI tanggal 6-9 Oktober 1953, dilancarkan pembersihan pada pimpinan tua, yang gagal dalam pemberontakan Madiun, dengan menunut pertanggung jawaban partai, dan pemilihan pimpinan baru. Aidit terpilih menjadi Sekjen. ${ }^{14}$ Alimin diberhentikan dari keanggotaan Politbiro, dan Tan Ling Djie diberhentikan dari keanggotaan CC (Central Comite). Susunan CC disempurnakan dan Politbiro Partai terdiri dari D.N. Aidit, M.H. Lukman, Njoto, Sudisman dan Sakirman. ${ }^{15}$

Pada Sidang Pleno CC PKI tanggal 6-9 Oktober 1953, dilancarkan pembersihan pada pimpinan tua, yang gagal dalam pemberontakan Madiun, dengan menunut pertanggung jawaban partai, dan pemilihan pimpinan baru. Aidit terpilih menjadi Sekjen. ${ }^{16}$ Alimin diberhentikan dari keanggotaan Politbiro, dan Tan Ling Djie diberhentikan dari keanggotaan CC (Central Comite). Susunan CC disempurnakan dan Politbiro Partai terdiri dari D.N. Aidit, M.H. Lukman, Njoto, Sudisman dan Sakirman. ${ }^{17}$

Pada tanggal 24 Juni 1961, Presiden Soekarno kembali dari perjalanan ke luar negeri. Kemudian melantik DPR-GR dengan menambah 22 ulama

\footnotetext{
12 Dalhar Muhammadun, Tanah Berdarah di Bumi Merdeka, Yayasan Advokasi

Transformasi Masyarakat, Solo, 2014, hlm.15.

${ }^{13}$ Soegiarso Soerojo, Siapa Menabur Angin Akan Menuai Badai (G30S/PKI dan Apa Peran Bung Karno),..hlm.83.

${ }^{14}$ Soegiarso Soerojo, Siapa Menabur Angin Akan Menuai Badai (G30S/PKI dan Apa Peran Bung Karno),..hlm.87.

${ }^{15}$ Busjarie Latif, Manuskrip Sejarah 45 Tahun PKI (1920-1965),..hlm.333.

${ }^{16}$ Soegiarso Soerojo, Siapa Menabur Angin Akan Menuai Badai (G30S/PKI dan Apa Peran Bung Karno),..hlm.87.

${ }^{17}$ Busjarie Latif, Manuskrip Sejarah 45 Tahun PKI (1920-1965),..hlm.333.
} 
sebagai anggota. Dan pada tanggal 15 Agustus Presiden melantik MPRS, terdiri dari 92 wakil daerah, 232 golongan fungsional, dan 283 anggota parlemen. Presiden Soekarno mengangkat Chairul Saleh sebagai Ketua, dan Mr. Ali Sastromidjojo (PNI), Idham Chalid (NU), D.N. Aidit (PKI) serta Mayen Inf. Wilujo Puspojudo sebagai wakil-wakil ketua. Aidit menjabat 3 kali periode kabinet yaitu Kabinet Dwikora I, Kabinet Kerja III dan Kabinet Kerja IV dengan menjabat posisi yang sama yaitu Wakil Ketua MPRS. Pada tanggal 27 Maret 1962 dibentuklah DPRS Gotong Royong, beranggotakan 261, terdiri dari 130 wakil-wakil dari 9 partai, dan 131 wakil-wakil dari 21 ormas golongan fungsional. PNI mendapatkan 44 kursi, NU 36, PKI 30, Protestan 6, Katholik 4, PSII 5, PERTI 2, MURBA 2, dan PARTINDO 1. ABRI mendapatkan 35 kursi. Dengan demikian bersama dengan golongan fungsional afiliasi PKI seperti GERWANI, PR, BTI, SARBUPRI, SOBSI. PKI menduduki 65 kursi di parlemen. ${ }^{89}$

\section{Peristiwa Menjelang G30S}

Ofensif Revolusioner dikomandokan Aidit pada tanggal 1 Januari 1965, lewat pesan Tahun Baru. "perkembangan politik dalam negeri ini tahun lalu ditandai Pidato Presiden 17 Agustus 1964 sekaligus komando Bung Karno untuk melakukan konfrontasi di semua bidang. Komando, agar seluruh rakyat melakukan massa aksi, dengan kegotong royongan berporos Nasakom dalam menentang Nekolim, menentang kaum komprador, kapitalis birokrat, tuan tanah, serta mendobrak kemacetan dalam pelaksanaan Undang-Undang Pokok Agraria dan Undang-Undang Pokok Bagi Hasil. Komando untuk mengganyang subversi, kontra revolusi dan Manipolis munafik."18

Pada paruh pertama tahun 1965, PKI semakin jaya dengan korban berderet panjang. Sesudah Masyumi dan Partai Sosialis Indonesia, musuh politik utama komunis pada bulan Agustus 1963 dibubarkan dengan tuduhan terlibat pemberontakan Pemerintahan Revolusioner Indonesia (PRRI) Permesta. Awal tahun 1965 disusul pembubaran Partai Murba dan Barisan Pendukung Soekarnoisme (BPS). RI ke luar dari PBB pada 7 Januari 1965, diumumkan Presiden Soekarno di depan rapat umum Anti Pangkalangan Militer Asing di Senayan. Alasannya PBB menghina RI dengan menerima Malaysia sebagai anggota Dewan Keamanan.

Pada tanggal 8 Maret 1965 Presiden Soekarno pada acara Hari Wanita Internasional di Istana Negara menyampaikan bahwa rakyat Indonesia siap untuk melawan negara boneka Malaysia yang dibuat oleh Amerika Serikat, Kanada, New Zealand, Inggris dan Australias merupakan bentuk dari Neo-

\footnotetext{
${ }^{18}$ Julius Pour, G30S, Fakta Atau Rekayasa, Kata Hasta Pustaka, Jakarta, 2013, hlm.20.
} 
Kolonialisme. Indonesia tidak akan menarik pasukannya di Kalimantan Utara dan Semenanjung Malaya sebelum adanya solusi terbaik untuk masalah ini. ${ }^{19}$

Aidit selaku Menko/Wakil Ketua MPRS dan Ketua CC PKI pada 10 Maret 1965 berbicara dihadapan peserta Kursus TAVIV PPI (Permusyawaratan Pemuda Indonesia) di Gedung Pemuda Jakarta bahwa rakyat Indonesia akan melawan serta mengganyang Amerika Serikat dan Malaysia atas proyek Neo-Kolonialisme yang sedang terjadi. Orang-orang revolusioner harus melawan dan anti terhadap imperialis Inggris dan AS. ${ }^{20}$

Pada 18 Mei 1965 Jenderal A.H. Nasution berbicara dihadap Pers di Amsterdam, Belanda bahwa Indonesia bukanlah negara komunis dan tidak bermaksud menjadi negara komunis. Karena Indonesia memiliki falsafah negara sendiri yaitu Pancasila. Tetapi keberadaan kaum komunis yang legal memainkan peranan yang penting dalam perjuangan revolusioner termasuk pengganyangan melawan Malaysia dan pemerintah Indonesia tidak akan menghalanginya. ${ }^{21}$

Bagi PKI massa pengganyangan Malaysia ini faedahnya; pertama memberikan kesibukan yang terus menerus kepad ABRI sehingga diharapkan ABRI akan dapat melupakan PKI sebagai musuhnya; kedua mendorong ABRI untuk lebih terikat lagi kepada bantuan peralatan dan persenjataan kepada negara-negara Blok Sovyet dan RRT, ketiga mengusahakan terus menerus agar sukarelawan-sukarelawan dari PKI dapat dipersenjatai; keempat memperjuangkan supaya dibentuk angkatan ke $\mathrm{V}$ yaitu buruh dan tani yang dipersenjatai dalam meningkatkan konfrontasi Malaysia. ${ }^{22}$

Gertakan PKI semakin meningkat sejak bulan Mei 1965, diawali aksi sepihak yang dibungkus dalam pelaksanaan Landreform. Di Mantingan, Jawa Timur, massa komunis dengan dipelopori anggota Barisan Tani Indonesia (BTI) berusaha mengambil paksa tanah wakaf seluas 150 hektar milik Pondok Pesantren Gontor, Ponorogo. Aksi sepihak tersebut segera memicu konflik horizontal di lapangan, sebagaimana terjadi tanggal 14 Mei 1965 di areal Perkebunan Negara Bandar Betsy, Sumatera Utara. Seorang perwira pertama Angkatan Darat yang juga petugas perkebunan. Pembantu Letnan II Soedjono, menarik traktir mogok. Tindakan itu dihadang oleh massa BTI, karena mereka

\footnotetext{
${ }^{19}$ Indonesia Tidak Gentar Dengan Adanya Active Aid A.S Kepada Malaysia, Arsip Statis, Perpustakaan Dinas Sejarah Angkatan Darat, 10 Maret 1965. Muhammad Ihsan Aulia, 6 September 2019.

${ }^{20}$ Active Aid A.S Kepada Malaysia Harus Dijawab Dengan Melawan A.S Lebih Aktif.Arsip Statis, Perpustakaan Dinas Sejarah Angkatan Darat, 10 Maret 1965. Muhammad Ihsan Aulia, 6 September 2019.

${ }^{21}$ Sukarelawan-sukarelawan Indonesia Bukan Urusan Negara Melainkan Adalah Urusan Revolusi.Arsip Statis, Perpustakaan Dinas Sejarah Angkatan Darat, 10 Maret 1965. Muhammad Ihsan Aulia, 6 September 2019.

${ }^{22}$ Dinas Sejarah Tentara Nasional Indonesia Angkatan Darat, Komunisme dan Kegiatannya di Indonesia, Bandung, 1985, hlm.249.
} 
merasa areal tersebut adalah tanah garapannya. Segera muncul perselisihan, Soedjono tewas dicincang massa, dikeroyok dan dibantai secara beringas. ${ }^{23}$

Pada tanggal 23 Mei 1965 PKI merayakan HUT ke-45 secara besarbesaran. Tamu-tamu berdatangan dari negara-negara komunis yaitu RRC, Albania, Korea, Vietnam, dan PKUS. Jakarta dipenuhi dengan poster-poster raksasa, spanduk-spanduk, patung-patung tokoh komunis. Gambar Presiden Soekanro dipajang sama besarnya dengan D.N. Aidit, Lenin, dan Karl Marx di beberapa jalan di Ibu Kota. Bendera-bendera palu-arit dipasang sampai ke pelosok-pelosok kampung.. Jakarta pada waktu sudah berubah wajah seolaholah sebagai Ibu Kota negara komunis. SOBSI Jakarta membentuk barisan semut merah. Darimana datangnya dana yang demikian besar, orang tidak tahu. Ada yang mengatakan salah satu kedutaan besar negara sosialis menyumbangkan macam-macam barang, mungkin juga dana. Juga dari para Cina BAPERKI. Malahan juga dari para pejabat sipil, dan beberapa oknum pejabat ABRI. ${ }^{24}$

Pada tanggal 9 Agustus 1965, Aidit menyelenggarakan rapat Politibiro pertama di markas besar partai di Kramat Raya 81, Jakarta. Rapat tersebut membahas tentang situasi terkini dan mengembangkan strategi-strategi yang tepat untuk mencapai tujuan partai dibawah kondisi-kondisi domestik dan internasional yang telah banyak berubah, yang menuntut langkah-langkah darurat dan cepat. Rapat-rapat selanjutnya dilaksanakan pada 26 dan 28 Agustus 1965.

Rapat pertama Politbiro yang terdiri dari 8 anggota yang diselenggarakan pada 9 Agustus 1965, dan dihadiri oleh 7 anggota tetap: Aidit, Lukman, Sudisman, Ir. Sakirman, Anwar Sanusi, Njoto dan Njono. Adjitorop, anggota kedelapan, tidak hadir karena tengah berkunjung ke Cina. ${ }^{25}$

Brigjen Polisi Soetarto, Kepala Staf BPI (Badan Pusat Intelijen), memberi Aidit informasi mengenai keberadaan Dewan Jenderal dan rencanarencananya. Lebih jauh lagi Aidit mengatakan bahwa informasi itu kemudian dicek oleh Dr.Soebandrio, Menlu merangkap Kepala Badan Pusat Intelijen itu, dan juga oleh Ali Sastromidjojo dari Partai Nasionalis Indonesia (PNI). Dr. Soebandrio sudah menyerahkan dokumen-dokumen yang bersangkutan kepada Presiden Soekarno mengenai Dewan Jenderal dan rencananya yang akan mengambil langkah PreEmptive untuk menggeser Presiden, terlepas dari prospek kesehatannya, dengan operasi yang akan dimulai pada atau sekitar 5 Oktober 1965.

\footnotetext{
${ }^{23}$ Julius Pour, G30S, Fakta Atau Rekayasa,...hlm.26.

${ }^{24}$ Soegiarso Soerojo, Siapa Menabur Angin Akan Menuai Badai (G30S/PKI dan Apa Peran Bung Karno),..hlm.217.

${ }^{25}$ Victor M. Fic, Kudeta 1 Oktober 1965 Sebuah Studi Tentang Konspirasi, Yayasan Obor Indonesia, Jakarta, 2005, hlm.115.
} 
Menyusul rapat Politbiro tersebut, Aidit mengundang Sjam kerumahnya pada tanggal 12 Agustus 1965, untuk memberitahu dia mengenai keputusan Politbiro untuk melancarkan suatu pukulan pre-emptive yang cepat dan menentukan untuk memenggal pucuk pimpinan $\mathrm{AD}$, dan memerintahkan dia membangun sebuah komando, yang terdiri dari perwira-perwira progresif revolusioner, untuk melaksanakannya.

Sjam langsung mendiskusikan instruksi-instruksi Aidit dengan pembantu-pembantunya, Pono dan Walujo, mereka meneliti nama-nama perwira yang sekiranya bisa dikendalikan untuk direkrut dalam operasi ini. Diskusi Sjam, Pono dan Walujo difokuskan pada Kolonel Latief, Komandan Brigade Infantri I Garnisun Jakarta, Mayor Udara Sujono, Komandan Resimen Keamanan AURI, Letkol Untung, Komandan Batalyon Pengawal Istana Cakrabirawa.

Politbiro melaksanakan sepuluh kali rapat sepanjang bulan September dari tanggal 6-30 September 1965. Rapat terakhir dilaksanakan pada 29 September 1965 dengan pembahasan bahwa jenderal yang akan dijadikan target gugus tugas Pasopati: Jenderal Abdul Haris Nasution, Letjen Achmad Yani, Mayjen Suwondo Parman, Mayjen Suprapto, Mayjen M.T. Haryono, Brigjen D.I. Pandjaitan, Brigjen Sutoyo Siswomihardjo dan Brigjen Achmad Sukendro. Dalam kesempatan itu Sjam mengusulkan supaya Moch. Hatta, Chairul Saleh dan Sukarni juga ikut diculik.

Hari Peristiwa Berdarah Berlangsung

Pada dini hari 30 September, Walujo memberitahu Letkol Udara Heru Atmodjo yang bertindak sebagai penghubung antara Biro Chusus dengan Marsekal Madya Omar Dhani bahwa D-Day untuk operasi itu telah ditetapkan subuh 1 Oktober, dan bahwa pada hari itu Brigjen Supardjo akan memimpin pasukan untuk menculik para jenderal. ${ }^{26}$ Omar Dhani membuka rapat bersama para penasehat puncaknya di rumahnya pada 30 September malam, yang dihadiri oleh Marsekal Madya Udara Maki, Komodor Dewanto, Komodor Handoko, Letkol Udara Heru Atmodjo, dan Komodor Leo Wattimena. Heru melaporkan tentang Operasi Takari, penempatan pasukan-pasukan pemukul dan detail-detail yang berhubungan dengan penahanan dan eksekusi jenderaljenderal AD. Komodor Handoko memerintahkan Kopral Muhammad Abang untuk menyediakan 17 kendaraan bagi pasukan Supardjo. Pasukan pemberontak juga diizinkan mengambil 3.000 pucuk senjata di gudang senjata Mampang.

Pada pukul 02.00 di Lubang Buaya, Letnan Kolonel (Inf) Untung Samsoeti, Komandan Batalyon I Resimen Tjakrabirawa bersama Brigadir Jenderal Soepardjo, Kolonel (Inf) Abdul Latief, Sjam dan Pono melakukan Briefing dilanjutkan kemudian semua pasukan untuk bersiap-siap melakukan

${ }^{26}$ Victor M. Fic, Kudeta 1 Oktober 1965 Sebuah Studi Tentang Konspirasi,...hlm.155. 
operasi. Pada pukul 03.00 Pasukan dibagi-bagi seperti pasukan pemukul (Pasopati) dipimpin Letnan Infanteri Dul Arief bertugas untuk menculik para jenderal dikediamannya. Pasukan teritorial (Bhimasakti) dipimpin Kapten Infanteri Suradi dengan tugas mengamankan istana Presiden, stasiun radio, pusat komunikasi, kantor pos dan objek-objek vital lainnya di kota. Pasukan cadangan (Gataotkaca) dipimpin Mayor Udara Gathut Sukrisno, meliputi para sukarelawan yang sudah dilatih di Pondok Gede, diberi tugas mengkoordinasikan aktivitas-aktivitas di Pondok Gede.

RRI dikuasai oleh Gerakan 30 September sekitar pukul 05.00 pagi haritanggal 1 Oktober 1965. Ini merupakan pelaksanaan dari pertemuan antara Tjugito (anggota PKI) dengan Kepala Direktorat RRI/TVRI Sukirman pada tanggal 30 September 1965. Siaran pengumuman Gerakan 30 September itu kemudian disusul dengan Perintah Harian Menteri Panglima Angkatan Udara Laksamana Madya Omar Dhani pada pukul 09.00 dalam bentuk radiogram, yang menyatakan, "Pada tanggal 30 September 1965 malam telah diadakan Gerakan oleh G3OS, 1965 untuk mengamankan dan menyelamatkan Revolusi dan Pemimpin Besar Revolusi terhadap subversi CIA.

Pada pukul 05.00 semua jenderal sudah diculik dan diamankan di Lubang Buaya dengan bermaksud untuk segera diadili di depan rakyat atas usaha mereka untuk melakukan kudeta terhadap pemerintah. Tetapi Menko Hankam/KASAB terluka dan masih hidup, masalah besar akan menghadang. Sjam mendiktekan pesan kepada Soejono yang menyatakan bahwa mereka harus dibunuh, meskipun hal tersebut bertentangan dengan rencana awal. Dengan intruksi tersebut, Soejono memerintahkan Gerwani di Pondok Gede diberi kewenangan untuk menyiksa dan membunuh para jenderal yang masih hidup dan melemparkan tubuh mereka ke sumur tua di Lubang Buaya.

Beberapa saat sebelum pukul 10.00 Brigjen Supardjo tiba naik mobil Nissan patrol didampingi oleh Letkol (Udara) Heru Atmodjo, Mayor (Inf) Sukirno dan Mayor (Inf) Bambang Supen, dua komandan batalyon pemberontak. Supardjo memberi salam dan melaporkan bahwa dia, dan kelompok perwira muda, telah melaksanakan perintah menggagalkan kudeta melawan Presiden yang di prakarsai oleh Dewan Jenderal, dan meminta Presiden memberikan penghargaan atas apa yang telah mereka lakukan. Selanjutnya Supardjo melaporkan bahwa beberapa jenderal sudah diamankan, tetapi Nasution lolos dari penangkapan, Presiden kemudian mengomentari bahwa hal tersebut biasa dalam revolusi. Lalu Presiden menanyakan kepada Supardjo tentang bukti bahwa adanya Dewan Jenderal yang akan melakukan kudeta terhadap dirinya. Supardjo berdalih bahwa laporan lengkapnya ada pada laporan Untung.

Kemudian Presiden membuat tiga keputusan penting. Pertama, Presiden menyelenggarakan rapat presidium Kabinet Dwikora dan mengundang Perdana Menteri untuk hadir. Pesan radio dikirim kepada 
Waperdam I Dr. Subandrio, agar datang dari Sumatra, dan kemudian Waperdam II Dr. Leimena, dihubungi lewat pesan untuk segera datang ke Halim untuk rapat mendesak kabinet. Waperdam III Chairul Saleh, sedang memimpin team para pejabat berkunjung ke Cina. Presiden kemudian dikelilingi oleh tiga Panglima angkatan yang siap melaksanakan apapun. Pangal dan Pangak dipanggil karena untuk AURI sudah ada Dhani. Kedua, Presiden memutuskan tidak mengundang Aidit ke Pusat Komando untuk menemuinya menegosiasikan penetapan politik pasca-pembersihan: meskipun dia duduk sebagai menteri di kabinet Dwikora.

Aidit paham benar, bahkan sebelum Supardjo kembali ke Cenko I sekitar pukul 12 siang untuk melapor kepada Sjam dan Untung tentang pertemuannya dengan Presiden, bahwa pilihannya mengenai jalan pintas menuju kekuasaan telah tumbang di Pusat Komando Halim. Tindakan yang dipilihnya untuk memperoleh kekuasaan berakhir dengan kemenangan telak bagi Presiden. Aidit tahu bahwa Presiden telah memerintahkan Supardjo menghentikan seluruh gerakan, hal ini mengasumsikan kekuatan penuh Kepala Negara, dan bahwa Supardjo telah berkhianat dengan berperan serta mengembalikan Presiden ke kedudukannya semula. ${ }^{27}$ Aidit dan para koleganya di rumah Suwardi di Halim gagal menerapkan serangakaian aksi itu meskipun pengingkaran Presiden terhadap perjanjiannya dengan Aidit benar-benar bisa menjamin dilakukannya tindakan itu, yang sepenuhnya sesuai dengan maksud Politbiro. Presiden mengizinkan RRI mengumumkan pada pukul 13.00 bahwa Presiden tetap bertindak sebagai Kepala Negara dan mau bernegosiasi dengan Aidit.

Selanjutnya semua perangkat pasukan yang memberontak segera dipadamkan oleh KOSTRAD dibawah Mayjen Soeharto. Soekarno akhirnya meninggalkan Halim atas keinginannya sendiri pada 10.30 malam, 1 Oktober, dan tiba di Bogor lewat tengah malam. Soeharto menyatakan bahwa ia menelepon seseorang yang dapat dipercaya di Bogor, Kol.Alex, untuk pergi ke istana untuk melihat langsung apakah Soekarno telah tiba. Kemudian Kol. Sarwo Edhie, Komandan RPKAD, dikirim ke Bogor untuk meyakinkan bahwa Soekarno tidak hanya berada di sana namun ia tidak pergi ke tempat lain lagi. ${ }^{28}$

Pada pukul 6 pagi tanggal 2 Oktober, RPKAD pimpinan Sarwo Edhie menyerbu masuk ke pangkalan Halim. RPKAD dapat menguasai PAU tanpa perlawanan. Laksda Sri Mulyono Herlambang dapat meyakinkan RPKAD tak ada pesawat yang terbang ke Kostrad. Diketahui D.N. Aidit telah pergi ke Yogyakarta dengan menggunakan pesawat milik AU.

\footnotetext{
${ }^{27}$ Victor M. Fic. Kudeta 1 Oktober 1965 Sebuah Studi Tentang Konspirasi,...hlm.183.

${ }^{28}$ Benedict R. OG Anderson dan Ruth T Mc Vey, Kudeta 1 Oktober 1965: Sebuah Analisis Awal, LKPSM, Yogyakarta, 2001, hlm.83.
} 
Tanggal 4 Oktober 1965, dilakukan penggalian serta pengangkatan jenazah-jenazah yang telah disembelih petualang Gestapu dari dalam lubang sumur tua, sedalam 12 meter dengan garis tengah $3 / 4$ meter, terletak di Lubang Buaya dalam daerah Pangkalan Udara Halim Perdanakusumah. ${ }^{29}$ Proses pengangkatan jenazah dari dalam sumur tua dilaksanakan oleh pasukan RPKAD dan Kesatuan Intai Amphibi (KIPAM) Korps Komando (KKO) TNI AL pimpinan Kapten KKO Winanto. Pangkostrad Mayjen Soeharto memimpin langsung pengangkatan tujuh jenazah. Pengangkatan jenazah dimulai pukul 12.05 WIB dan jenazah pertama yang berhasil diangkat Lettu P.A. Tendean. Selanjutnya berturutturut diangkat jenazah Mayjen S. Parman, dan Mayjen R. Soeprapto yang terikat menjadi satu, jenazah Mayjen M.T. Harjono, jenazah Brigjen Soetojo S, jenazah Letjen A. Yani, dan yang terakhir jenazah Brigjen D.I. Pandjaitan pada pukul 13.40 WIB. Selanjutnya jenazah dibawa ke Rumah Sakit Pusat Angkatan Darat (RSPAD) Gatot Subroto untuk divisum.

Tanggal 5 Oktober 1965, upacara pemakaman jenazah tujuh Pahlawan Revolusi berlangsung di Taman Makam Pahlawan Kalibata. Sejalan dengan itu, pembersihan di daerah Cibinong berhasil menangkap tiga anggota AURI dan seorang prajurit Batalyon 530/Para yang ikut serta dalam petualangan. Upacara pemberangkatan tujuh jenazah perwira TNI AD di Markas Besar Angkatan Darat (MBAD), dengan inspektur upacara MenkoHankam/Kasab Jenderal A.H. Nasution. Atas jasa-jasanya, pemerintah menganugerahi gelar Pahlawan Revolusi dan menaikan pangkatnya satu tingkat lebih tinggi dari pangkat semula. Masing-masing jenazah Pahlawan Revolusi diletakan di atas panser Saraceen yang dijaga oleh seorang perwira TNI AD. Tepat pukul 10.00 WIB, dengan diiringi tembakan salvo dan suara genderang, ketujuh jenazah diberangkatkan menuju Taman Makam Pahlawan Kalibata, Jakarta. Iringiringan kendaraan jenazah didahului kendaraan pengawal kehormatan. Panser pertama membawa jenazah Letjen A. Yani dan diikuti panser jenazah Pahlawan Revolusi lainnya.

\section{Aidit Pasca Peristiwa G30S}

Setelah kembali ke Cenko II, Sjam meminta Sujono agar mendekati Omar Dhani untuk meminta sebuah pesawat bagi Aidit, Sujono melapor kembali menjelang pukul 23.00 bahwa ia telah mendapatkan sebuah pesawat, dan saat itu juga diputuskan bahwa Aidit harus pergi ke Yogyakarta, ditemani oleh sekretarisnya, Kusno dan Walujo. Segera setelah pesawat diisi bahan bakar dan siap, Sjam mengeluarkan Aidit dari rumah Suwardi dan

\footnotetext{
${ }^{29}$ Julius Pour, G30S, Fakta Atau Rekayasa,...hlm.497.
} 
membawanya ke landas pacu untuk menaiki pesawat itu, yang tinggal landas pada pukul 01.00 pagi tanggal 2 Oktober 1965 dengan tujuan Yogyakarta. ${ }^{30}$

Dari Pangkalan Udara Maguwo Aidit bergegas menuju kota Yogyakarta untuk mengadakan pertemuan darurat dengan para pimpinan setempat. Ia melaporkan secara rinci peristiwa yang terjadi pada hari sebelumnya, dan menjelaskan sebab-sebab terjadinya komplikasi-komplikasi yang dialami kudeta di Jakarta. Pertemuan itu kemudian membahas penilaian tentang kemungkinan membentuk kelompok-kelompok bersenjata setempat untuk mendukung Dewan Revolusi Untung, dan menyimpulkan bahwa ini tidak mungkin. ${ }^{31}$

Kemudian siang hari setelah pertemuan pada 2 Oktober, Aidit meninggalkan Yogyakarta menuju Semarang, tempat Lukman, Sujono Atmo dan pimpinan puncak PKI propinsi mengadakan pertemuan darurat. Pada larut petang 2 Oktober, Aidit dan Lukman berangkat menuju Bojolali dan kemudian Solo, tempat pertemuan juga diadakan dengan pimpinan partai propinsi dan pimpinan militer. Namun di Solo, Aidit tidak berhasil mendapat persetujuan partai untuk menerima keputusan pertemuan Semarang. Cara Aidit melaksanakan operasi di Jakarta mendapat kecaman bertubi-tubi dari anggotaanggota yang radikal yang menuntut perjuangan bersenjata dengan segera, dan ketika diadakan pemungutan suara, Aidit kalah suara, oleh kombinasi suara Suwarno, Suwardi dan Utomo Ramelan, Walikota Solo yang berani itu. ${ }^{32}$

Dalam keadaan partai yang terpecah sangat dalam seperti itu, diadakan pertemuan Politbiro pada 5 Oktober di Blitar, Jawa Timur -hanya Aidit dan Lukman yang hadir, dari enam anggota tetap dan dua calon anggota untuk menyusun sebuah pernyataan Politbiro PKI, dan surat Aidit kepada Presiden. Hanya dalam waktu tiga minggu, tim intelijen Brigif IV sudah berhasil melacak jejak Aidit. Sampai akhirnya masuk sebuah laporan berkwalinasi A1, terjamin kebenarannya. Bahwa pada tanggal 21 November 1965, persembunyian Aidit akan pindah dari Kleco, bagian Barat kata Solo, ke Kampung Sambeng. Sesudah menerima info A-l tersebut, jaring-jaring perangkap segera ditebar. Jasir mengerahkan pasukannya menuju Kampung Sambeng, sekitar 300 meter dari Stasiun Kereta Api Solo Balapan.

Aidit kemudian ditangkap dan dibawa oleh Kolonel (Inf) Jasir Hadibroto, rencananya akan dihadapkan langsung ke Jakarta, tetapi kemudian Jip yang membawa Aidit dibelokan ke Markas Batalyon Infantri 444. Dibelakangnya ada sumur tua, disana Aidit ditembak oleh Kolonel (Inf) Jasir Hadibroto pada tanggal 23 November 1965.

\footnotetext{
${ }^{30}$ Victor M. Fic, Kudeta 1 Oktober 1965 Sebuah Studi Tentang Konspirasi,...hIm.228.

${ }^{31}$ Victor M. Fic, Kudeta 1 Oktober 1965 Sebuah Studi Tentang

Konspirasi,...hlm.248.

${ }^{32}$ Victor M. Fic, Kudeta 1 Oktober 1965 Sebuah Studi Tentang Konspirasi,...hlm.249.
} 


\section{Simpulan}

Aidit lahir pada tanggal 30 Juli 1923 di Jalan Belantu Nomor 3 Pangkalalang, Tanjungpandan dengan nama Achmad Aidit. Nama ayahnya adalah Abdullah Aidit, sedangkan ibunya bernama Mailan. Abdullah Aidit merupakan mantri kehutanan, pegawai boschwezen. Aidit mempunyai saudara kandung yaitu Achmad Aidit, Basri Aidit, Ibrahim Aidit (meninggal ketika kecil), dan Murad Aidit.

Aidit kecil menamatkan sekolahnya di HIS (Hollands Inlandsche School) atau sekolah dasarnya anak-anak sekarang. Setelah luluas HIS, Aidit dikirim ke Batavia untuk masuk ke sekolah dagang bernama MHS (Middlestand Handels School). D.N Aidit menyukai buku-buku klasik tentang politik dan ekonomi. Dia mempelajari berbagai buku yang sifatnya komunis dan sosialis. Dia mulai membaca buku tebal Das Kapital karya Karl Marx (1818-1883), mulai mengenal dan mempelajari pemikiran Friedrich Engels (1820-1895), Fuerbach, Friedrich Nietszhe (1844-1900), dan yang lainnya seperti karya Mao Zedong dan pemimpin Tiongkok lainnya.

D.N. Aidit menjadi Sekjen CC PKI pada Oktober 1953 melalui Sidang Pleno dengan membersihkan golongan tua terlebih dahulu yang gagal dalam pemberontakan Madiun 1948. Pada tahun 1959, Aidit merubah istilah Sekjen menjadi Ketua, sejak itu Aidit memimpin Partai Komunis Indonesia. Aidit menjabat 3 kali periode kabinet yaitu Kabinet Dwikora I, Kabinet Kerja III dan Kabinet Kerja IV dengan menjabat posisi yang sama yaitu Wakil Ketua MPRS.

Pada peristiwa G30S tahun 1965, Aidit ikut dalam merumuskan dan memerintakan untuk menjalankan penculikan para jenderal Angkatan Darat (Dewan Jenderal) terdiri dari Mayor Jenderal Siswondo Parman, Brigadir Jenderal Soetojo Siswomihardjo, Mayor Jenderal Soeprapto, Mayor Jenderal Harjono, Brigadir Jenderal Donald Pandjaitan dan Kapten Czi Pierre Tendean. Setelah peristiwa G30S gagal, Aidit pergi ke Yogyakarta, mencoba membangun lagi kekuatan di Jawa Tengah. Tetapi pada tanggal 21 November 1965 di tempat persembunyiannya di Kampung Sambeng, sekitar 300 meter dari Stasiun Kereta Api Solo Balapan. Aidit ditembak mati di belakang rumah Komandan Batalyon Infantri 444 Trisno di sumur tua di pinggiran Boyolali. 


\section{Daftar Pustaka}

\section{Arsip}

Active Aid A.S Kepada Malaysia Harus Dijawab Dengan Melawan A.S Lebih Aktif. 1965. Bandung. Perpustakaan Dinas Sejarah Angkatan Darat. Indonesia Tidak Gentar Dengan Adanya Active Aid A.S Kepada Malaysia. 1965. Bandung. Perpustakaan Dinas Sejarah Angkatan Darat

Sukarelawan-sukarelawan Indonesia Bukan Urusan Negara Melainkan Adalah Urusan Revolusi. 1965. Bandung. Perpustakaan Dinas Sejarah Angkatan Darat.

\section{Buku}

Aidit, D.N. 1952. Sejarah Gerakan Buruh Indonesia.Djakarta.Jajasan "Pembaruan".

Aidit, D.N. 1955. Lahirnja PKI Dan Perkembangannja (1920-1955).

Djakarta. Jajasan "Pembaruan".

Murad. 2005. Aidit Sang Legenda. Jakarta. Panta Rei.

Aidit, Sobron. 2003. Aidit (Abang, Sahabat dan Guru di Masa Pergolakan. Bandung. Nuansa Cendekia.

M. Fic, Victor. 2005. Kudeta 1 Oktober 1965 Sebuah Studi Tentang Konspirasi. Jakarta. Yayasan Obor Indonesia.

Muhammadun, Dalhar. 2014. Tanah Berdarah di Bumi Merdeka. Solo. Yayasan Advokasi Transformasi Masyarakat.

Pour, Julius. 2013. G30S, Fakta Atau Rekayasa. Jakarta. Kata Hasta Pustaka. Soerojo, Soegiarso. 1988. Siapa Menabur Angin Akan Menuai Badai (G30S/PKI dan Apa Peran Bung Karno). Jakarta. PT.Intermasa.

Tempo : Orang Kiri Indonesia. 2010. Aidit (Dua Wajah Dipa Nusantara). Jakarta. Kepustakaan Populer Gramedia.

Wikipedia. 2017. "Gerakan Rakyat Indonesia”, https://id.m.wikipedia.org, diakses pada tanggal 25 Mei 2019 pukul 17.00. 
Peran Dipa Nusantara Aidit...... | M Ihsan Aulia

$120 \mid \mathrm{H}$ is t o r i a M a d a i a 